\title{
Regulatory $B$ cells inhibit EAE initiation in mice while other $B$ cells promote disease progression
}

\author{
Takashi Matsushita, ${ }^{1}$ Koichi Yanaba, ${ }^{1}$ Jean-David Bouaziz, ${ }^{1}$ \\ Manabu Fujimoto, ${ }^{2}$ and Thomas F. Tedder ${ }^{1}$ \\ 1Department of Immunology, Duke University Medical Center, Durham, North Carolina, USA. 'Department of Dermatology, \\ Kanazawa University Graduate School of Medical Science, Kanazawa, Japan.
}

\begin{abstract}
EAE is a mouse T cell-mediated autoimmune disease of the CNS used to model the human condition MS. The contributions of B cells to EAE initiation and progression are unclear. In this study, we have shown that EAE disease initiation and progression are differentially influenced by the depletion of $B$ cells from mice with otherwise intact immune systems. CD20 antibody-mediated B cell depletion before EAE induction substantially exacerbated disease symptoms and increased encephalitogenic $T$ cell influx into the CNS. Increased symptom severity resulted from the depletion of a rare $I L-10$-producing $C D 1 \mathrm{~d}^{\text {hi }} \mathrm{CD5}^{+}$regulatory $\mathrm{B}$ cell subset (B10 cells), since the adoptive transfer of splenic B10 cells before EAE induction normalized EAE in B cell-depleted mice. While transfer of regulatory B10 cells was maximally effective during early EAE initiation, they had no obvious role during disease progression. Rather, $B$ cell depletion during EAE disease progression dramatically suppressed symptoms. Specifically, B cells were required for the generation of $\mathrm{CD}^{+} \mathrm{T}$ cells specific for $\mathrm{CNS}$ autoantigen and the entry of encephalitogenic $T$ cells into the CNS during disease progression. These results demonstrate reciprocal regulatory roles for $B$ cells during EAE immunopathogenesis. The therapeutic effect of $B$ cell depletion for the treatment of autoimmunity may therefore depend on the relative contributions and the timing of these opposing $B$ cell activities during the course of disease initiation and pathogenesis.
\end{abstract}

\section{Introduction}

MS is a common inflammatory and demyelinating disease of the human CNS. EAE is an induced autoimmune disease in mice that results in inflammatory demyelination of the CNS by $\mathrm{CD}^{+}$ $\mathrm{T}$ lymphocytes specific for CNS autoantigens such as myelin oligodendrocyte glycoprotein (MOG) (1). MS and EAE are similar in disease susceptibility, course, and histopathology. Since the adoptive transfer of neural antigen-specific T cells alone is sufficient to induce pathology (2), EAE is predominantly considered a $\mathrm{T}$ cell-mediated autoimmune disease. Specifically, IFN- $\gamma-$ and IL-17-producing $\mathrm{T}$ cell subsets are important for promoting EAE $(3,4)$, while IL-10 is important for EAE negative regulation $(5,6)$.

Contradictory roles for B cells in EAE pathogenesis have been demonstrated (7-10). Although autoantibody production is not essential for EAE induction or progression, MOG-specific autoantibodies can enhance demyelination and inflammation $(11,12)$. In addition, studies using double-transgenic mice with MOG-specific $\mathrm{T}$ and $\mathrm{B}$ cell antigen receptors have shown that $\mathrm{B}$ cells may function as antigen-presenting cells during EAE initiation $(13,14)$. More than $50 \%$ of these mice develop inflammatory demyelinating lesions in the CNS, while disease incidence is approximately $5 \%$ in MOG-specific T cell receptor-transgenic (TCR ${ }^{\mathrm{MOG}}$ ) mice. By contrast, both congenitally B cell-deficient mice and CD19-deficient mice with reduced $\mathrm{B}$ cell function develop a severe nonremit-

Nonstandard abbreviations used: B10 cells, IL-10-producing CD $1 \mathrm{~d}^{\text {hi }} \mathrm{CD} 5^{+}$B cell subset; MOG, myelin oligodendrocyte glycoprotein; TCR ${ }^{\text {MOG }}$, MOG-specific T cell receptor-transgenic (mice); Teff, effector T cell.

Conflict of interest: T.F. Tedder is a paid consultant for MedImmune Inc. and Angelica Therapeutics Inc.

Citation for this article: J. Clin. Invest. 118:3420-3430 (2008). doi:10.1172/JCI36030. ting form of $\operatorname{EAE}(7,10,15)$. Furthermore, B cell production of IL-10 can inhibit EAE development (10). Thereby, the apparently contradictory results obtained in studies of $\mathrm{B}$ cell contributions to EAE pathogenesis may reflect the involvement of multiple roles for B cells or different B cell subsets during disease pathogenesis (16). For example, regulatory IL-10-producing B cells (B10 cells), representing $1 \%-2 \%$ of spleen $B$ cells, have been recently identified within a unique $\mathrm{CD} 1 \mathrm{~d}^{\text {hi }} \mathrm{CD} 5^{+} \mathrm{B}$ cell subset (17).

$\mathrm{B}$ cell depletion in humans using CD20 mAb (rituximab) can be effective in treating patients with various autoimmune disorders such as rheumatoid arthritis and lupus (18-22). CD20 is a B cellspecific molecule that is first expressed on the cell surface during the pre- $\mathrm{B}$ to immature $\mathrm{B}$ cell transition but is lost upon plasma cell differentiation $(23,24)$. A recent phase II trial using rituximab has suggested clinical efficacy in MS patients (25); however, the mechanisms underlying the effect of B cell depletion on disease activity remain unknown. Alternatively, B cell depletion may exacerbate disease since B cells are reported to have regulatory functions during EAE development (10). In humans, B cell depletion using rituximab was recently suggested to exacerbate ulcerative colitis (26) and trigger psoriasis (27), both conditions representing $\mathrm{T}$ cell-mediated autoimmune conditions. Since human studies are primarily restricted to measuring changes in blood B cells, which represent less than $2 \%$ of all B cells outside of the bone marrow (28), mechanistic studies often fail to take into account the possible changes in tissue B cells. Therefore, it is important to assess whether and how B cells are involved in EAE pathogenesis using a preclinical mouse model of B cell depletion. In this study, B cells were depleted during the course of EAE using CD20 $\mathrm{mAbs}$ that eliminate mature B cells in mice with otherwise intact immune systems (29-31). 


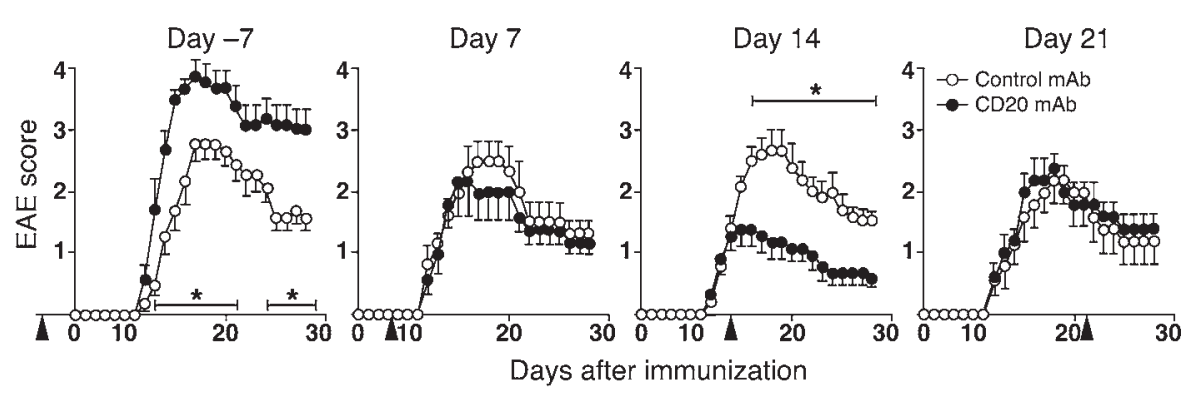

Figure 1

$B$ cells regulate EAE severity. B6 mice were treated with CD20 or control mAb $(250 \mu \mathrm{g})$ before or after MOG immunization (days $-7,7,14$, or 21$)$ and scored daily for EAE disease severity. Arrowheads indicate the day of mAb injection. Values represent (mean \pm SEM) EAE clinical scores from more than 5 mice in each group, with similar results obtained in 3 independent experiments. Significant differences between CD20 and control mAb-treated groups are indicated; ${ }^{*} P<0.05$.

\section{Results}

$B$ cells can inhibit and angment EAE. To assess the contributions of $\mathrm{B}$ cells during EAE induction or progression, mice were given CD20 $\mathrm{mAb}$ (MB20-11) 7 days before (day -7) or 7, 14, and 21 days after EAE induction. In mice treated with CD20 or control mAb, EAE symptoms first appeared around day 12 and both groups of mice had similar disease incidence (93\%-100\%; Figure 1 and Table 1). However, mice given CD20 mAb before MOG immunization (day -7) exhibited significantly worse disease as measured by tail and limb paralysis, impaired gait, and quadriplegia. This included a more severe peak in disease symptom severity and disease persisted longer when compared with control mAb-treated mice $(P<0.05$; Figure 1 and Table 1$)$. All mice depleted of B cells before MOG immunization developed clinical scores higher than 4 and had complete hind-limb paralysis, while only approximately $20 \%$ of control mAb-treated littermates had clinical scores of higher than 4 . Furthermore, $14 \%$ of mice treated with CD20 mAb before EAE induction were moribund and required euthanasia, while control mAb treatment did not alter EAE pathogenesis or lead to fatal complications. By contrast, CD20 mAb treatment after MOG immunization but prior to EAE development (day 7) did not alter disease severity when compared with control $\mathrm{mAb}$-treated littermates (Figure 1). However, CD20 mAb treatment after the appearance of EAE disease symptoms (day 14) dramatically reduced disease severity at subsequent time points when compared with control mAb-treated mice $(P<0.05$; Figure 1 and Table 1$)$. During the recovery phase of EAE (day 21), CD20 mAb treatment had no significant effect on clinical scores.

Quantitative microscopic examination of CNS tissues collected on day 18 from the day -7 and 14 treatment groups of mice revealed that $\mathrm{CD} 20 \mathrm{mAb}$ treatment before EAE induction resulted in more robust leukocyte infiltration into the CNS (65\% thoracic increase, $50 \%$ lumbar increase) and more significant demyelination (138\% thoracic increase, $87 \%$ lumbar increase) when compared with control mAb-treated mice $(P<0.05$; Figure 2$)$. CD20 mAb treatment during EAE development reduced leukocyte infiltration (65\% thoracic decrease, $68 \%$ lumbar decrease) and significantly reduced demyelination ( $90 \%$ decrease) when compared with control mAb-treated mice $(P<0.005$; Figure 2$)$. Thus, CD20 mAb treatment had profound effects on disease course and CNS leukocyte infiltration that was dependent on whether B cells were depleted before disease induction or after disease symptoms developed.
$C D 20$ mAb-induced B cell depletion. Whether the differential effects of CD20 mAb treatment on disease resulted from differences in $B$ cell depletion was assessed by quantifying B cell depletion in the different mouse groups. In mice treated with CD20 mAb on days -7 and 14 , the vast majority of mature B cells in the bone marrow, blood, spleen, and peripheral lymph nodes were depleted by day 18 after EAE induction, while control $\mathrm{mAb}$ treatment was without effect (Figure 3 and Table 2). CD20 mAb treatment also depleted the $\mathrm{CD} 1 \mathrm{~d}^{\text {hi }} \mathrm{CD}^{+} \mathrm{B}$ cell subset that includes B10 cells (Figure $3 \mathrm{~F}$ ). Peritoneal cavity B cells are more resistant to CD20 mAb-mediated depletion (29), which explains their less complete depletion 4 days after day $14 \mathrm{CD} 20 \mathrm{mAb}$ injection (Figure 3H). Nonetheless, MOG immunization did not significantly affect B cell subset depletion when compared with unimmunized mice (data not shown). Moreover, differences in $\mathrm{B}$ cell depletion did not explain increased EAE severity following early B cell depletion or decreased disease when $B$ cells were depleted late.

$B$ cell depletion abrogates MOG-specific Ab production. The effect of $B$ cell depletion on serum antibody responses was also assessed on days 18 (peak phase) and 28 (recovery phase) after MOG immunizations, since MOG-specific antibodies can enhance CNS demyelination and inflammation and increase EAE severity $(11,12)$. Control $\mathrm{mAb}$-treated mice produced significant IgM and IgG MOG-specific

\section{Table 1}

EAE clinical scores following CD20 mAb treatment ${ }^{A}$

$\begin{array}{lccc}\text { Group } & \text { Incidence }^{B} & \begin{array}{c}\text { Mean day } \\ \text { of onset }\end{array} & \begin{array}{c}\text { Mean maximum } \\ \text { score }\end{array} \\ \text { Untreatedc } & 9 / 10(90 \%) & 13.1 \pm 0.5 & 2.6 \pm 0.8 \\ \text { Day -7 control mAb } & 13 / 14(93 \%) & 13.0 \pm 0.5 & 2.8 \pm 0.6 \\ \text { Day -7 CD20 mAb } & 14 / 14(100 \%) & 12.9 \pm 0.5 & 4.3 \pm 0.4^{\mathrm{D}} \\ \text { Day 14 control mAb } & 14 / 15(93 \%) & 12.9 \pm 0.4 & 2.9 \pm 0.7 \\ \text { Day 14 CD20 mAb } & 14 / 15(93 \%) & 12.9 \pm 0.3 & 1.5 \pm 0.4^{\mathrm{E}}\end{array}$

AMice were treated with CD20 or control mAb $(250 \mu \mathrm{g}) 7$ days before or 14 days after MOG immunization. ${ }^{B}$ Assessment of clinical EAE includes the number of mice that developed disease, the day of disease onset (mean \pm SEM) among mice with $E A E$, and the maximum clinical score (mean \pm SEM) of each treatment group. CUntreated group was not treated with $\mathrm{mAb}$. The mean maximum clinical score obtained for the group over the entire observation period. Significant differences between CD20 versus control mAb-treated mice are indicated; $\mathrm{D} P<0.0005, \mathrm{E} P<0.005$. 
A

A Day $-7 \mathrm{CD} 20 \mathrm{mAb}$

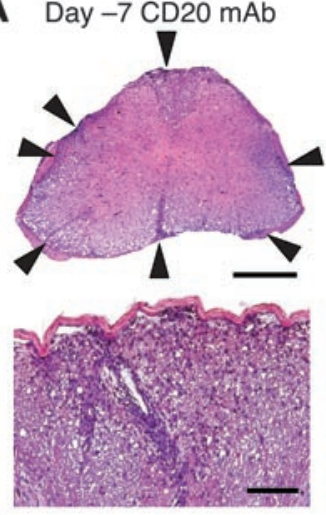

B

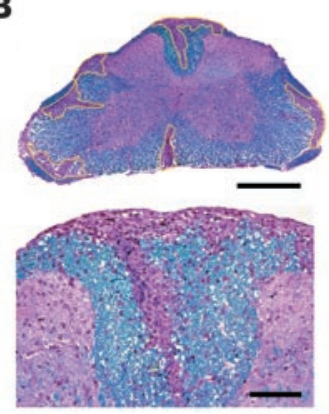

C

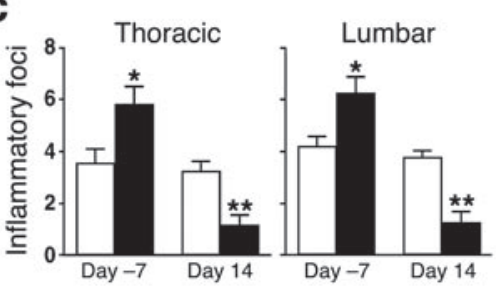

Control mAb
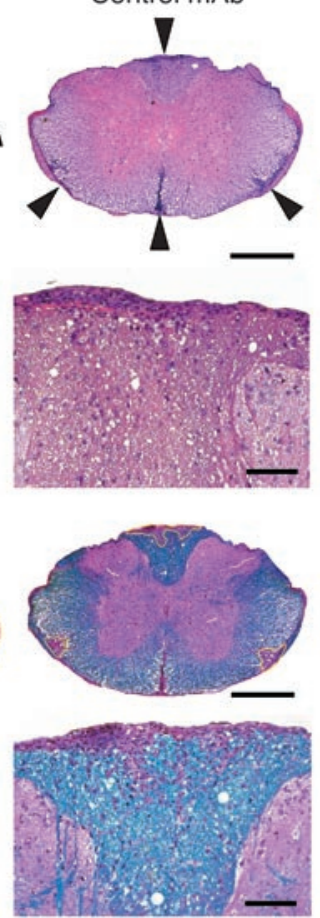

D
Day 14 CD20 mAb
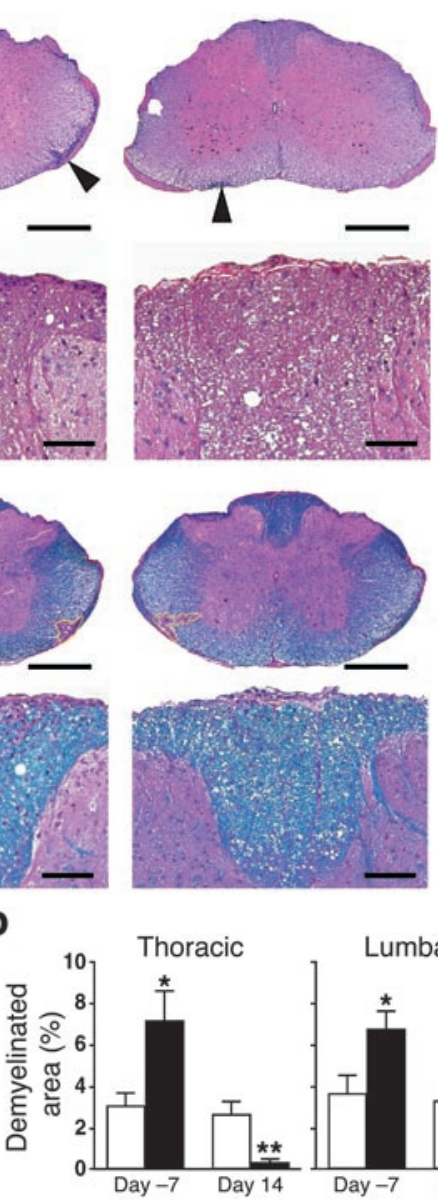

Lumbar

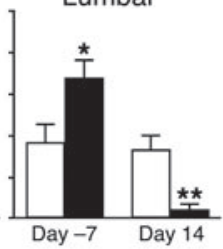

\section{Figure 2}

Quantitative EAE histopathology following B cell depletion as in Figure 1. (A and B) Representative lumbar spinal cord sections harvested 18 days after MOG immunizations ( $n \geq 4$ mice per group) show (A) inflammation (H\&E staining) and (B) demyelination (Luxol Fast Blue staining). Upper panels are low magnification (scale bar: $0.5 \mathrm{~mm}$ ). Lower panels are high magnification (scale bar: $0.01 \mathrm{~mm}$ ). (A) Arrowheads indicate inflammatory foci. (B) Yellow traced areas indicate demyelination. (C) Bar graphs indicate (mean \pm SEM) numbers of inflammatory foci and (D) demyelinated area, with significant differences between CD20 (black bars) and control mAb-treatments (white bars) indicated; * $P<0.05$, ${ }^{* \star} P<0.005$. Similar results were obtained in at least 2 independent experiments. antibody responses by day 18 after immunization when compared with unimmunized littermates (Figure 4; $P<0.001$ ). MOG-specific IgG antibody levels increased in parallel with disease progression, while MOG-specific IgM antibody levels decreased significantly by day $28(P<0.05)$. B cell depletion before MOG immunization (day -7) completely abrogated MOG-specific IgM and IgG antibody production. B cell depletion after disease development (day 14) significantly inhibited both MOG-specific IgM and IgG antibody production at the peak of disease $(50 \%, P<0.001 ; 45 \%, P<0.01$; respectively) and $\operatorname{IgG}$ production during the recovery phase $(48 \%$, $P<0.01$ ), consistent with results obtained in CD20 mAb-treated mice when using other immunogens (32). Thus, B cell depletion before and during EAE development significantly attenuated autoantibody production, which did not correlate with increased EAE severity following early B cell depletion.

$B$ cell depletion modifies encephalitogenic $T$ cells within the CNS. To assess whether CNS-infiltrating T cells were affected by B cell depletion, total $\mathrm{CD}^{+} \mathrm{T}$ cell numbers and the frequencies of MOGspecific effector $\mathrm{T}$ cells (Teffs) and Tregs were quantified on day 18 using $\mathrm{MOG}_{38-49} / \mathrm{IAb}$ (MHC class II) tetramers. MOG-specific $\mathrm{T}$ cells preferentially accumulated within the CNS but were only detected at very low frequencies in spleen and lymph nodes (Figure $5 \mathrm{~A})$. Total CD4 $4^{+} \mathrm{T}$ cell (120\% increase) and MOG-specific Teff numbers (207\% increase) in the CNS were significantly expanded following $\mathrm{B}$ cell depletion before EAE induction (day -7) when compared with control mAb-treated littermates $(P<0.05)$. The number of MOG-specific Tregs was not changed in B cell-depleted mice, which resulted in a significantly higher ratio of Teffs/Tregs $(P<0.01)$. Conversely, total CD4 ${ }^{+} \mathrm{T}$ cell, MOG-specific Teff, and Treg numbers within the CNS were significantly reduced $(62 \%$, $70 \%$, and $71 \%$ decrease, respectively) in mice depleted of B cells during EAE development (day $14 ; P<0.05$ ).

Since IFN- $\gamma$ and IL-17 play critical roles in EAE development $(3,4,33)$, their expression by CNS-infiltrating $\mathrm{CD}^{+} \mathrm{T}$ cells was assessed 18 days after MOG immunization. B cell depletion before EAE induction (day -7) significantly increased the numbers of IFN- $\gamma$ and IL-17 producing CD $4^{+}$T cells within the CNS as analyzed by intracellular cytokine staining (107\% and $147 \%$ increase, $P<0.05$; Figure 5B). Conversely, B cell depletion during EAE development (day 14) resulted in significantly reduced numbers of IFN- $\gamma$ and IL-17 producing $\mathrm{CD}^{+} \mathrm{T}$ cells $(73 \%$ and $64 \%$ decrease, $P<0.05$ ). Thus, B cell depletion before EAE induction increased encephalitogenic $\mathrm{CD} 4^{+} \mathrm{T}$ cell expansion within the CNS, whereas B cell depletion during EAE development reduced encephalitogenic $\mathrm{CD}^{+} \mathrm{T}$ cell numbers.

$B$ cell depletion during EAE development reduces antigen-specific $T$ cell proliferation. B cells are important for encephalitogenic $\mathrm{T}$ cell activation $(13,14)$ and for antigen-specific $\mathrm{T}$ cell proliferation in other models $(34,35)$. Therefore, the effects of $B$ cell depletion on antigen-specific $\mathrm{T}$ cell proliferation in mice with 
A

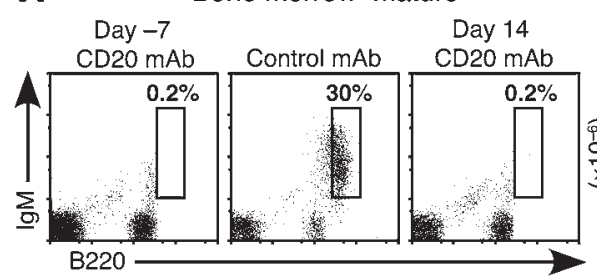

C

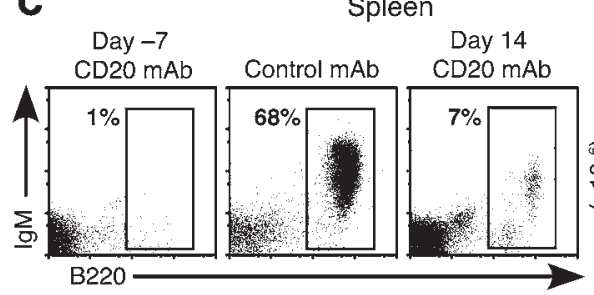

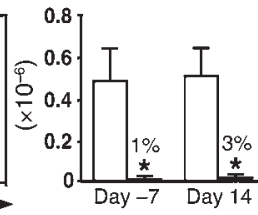

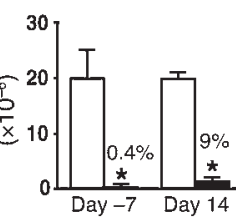

B
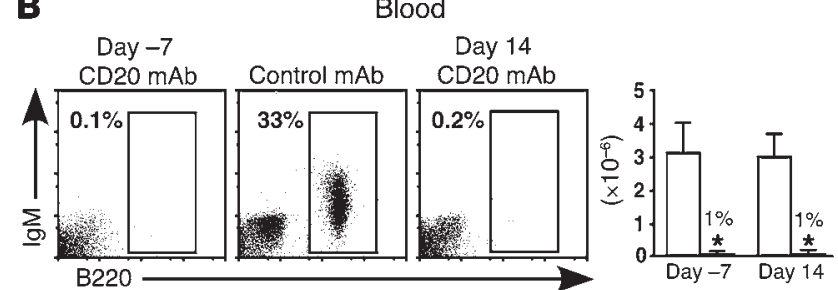

D
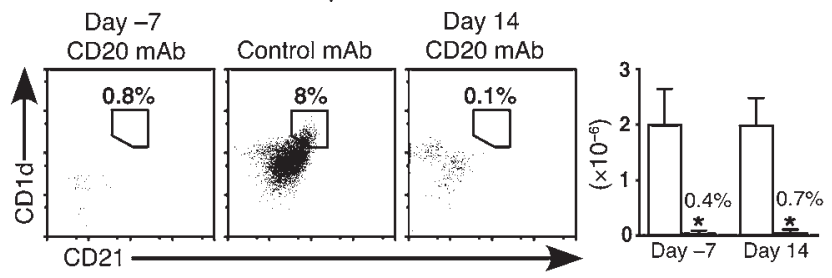

E

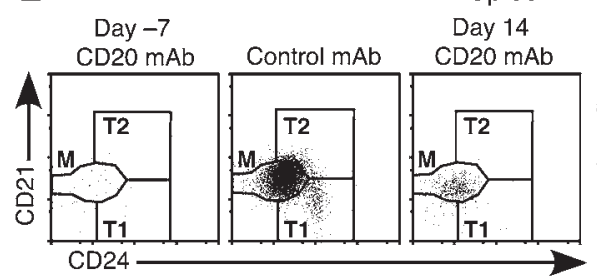

Spleen-T1, T2, and mature

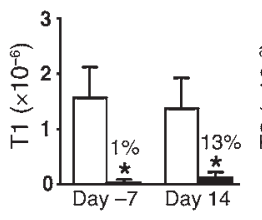

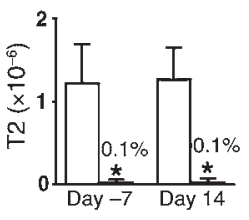

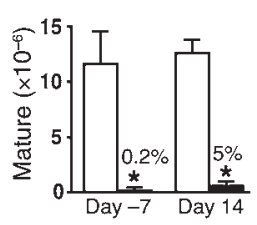

F

Spleen B10 cells

G

Lymph node
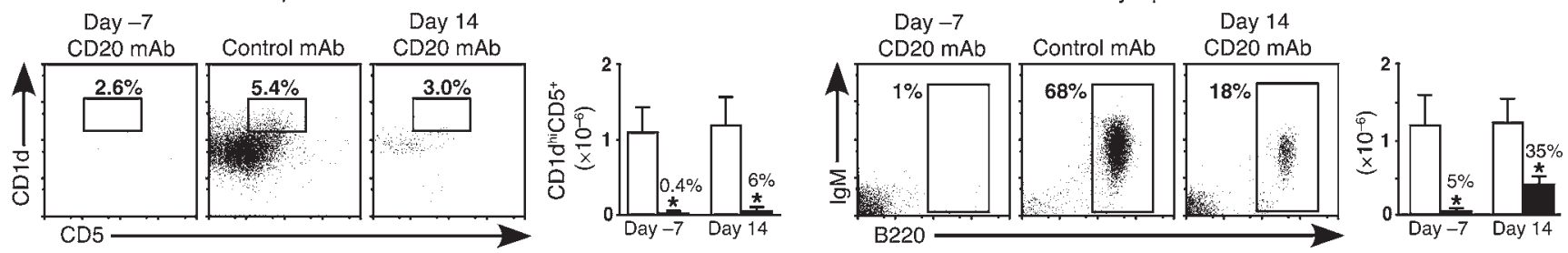

H

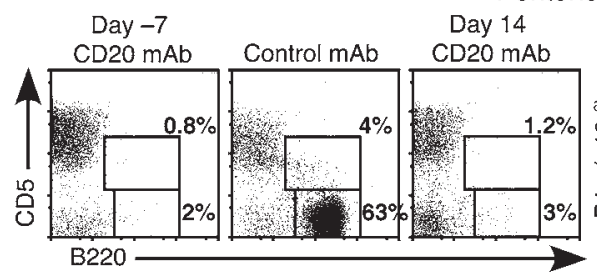

Peritoneal cavity-B1a, B1b, and B2
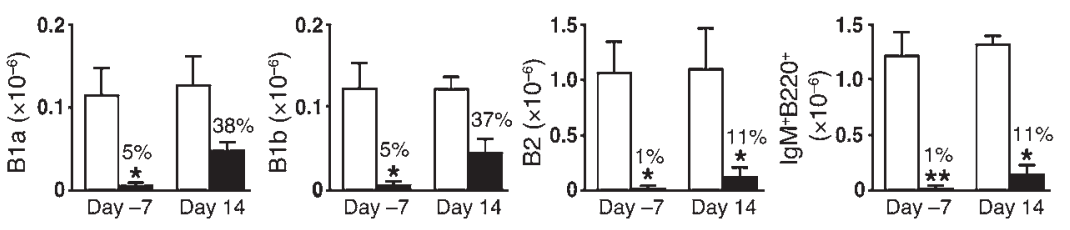

Figure 3

CD20 mAb-induced B cell depletion in EAE mice. B6 mice were treated with CD20 or control mAb 7 days before or 14 days after MOG immunization. Representative depletion of B cells from the $(\mathbf{A})$ bone marrow, $(\mathbf{B})$ blood, $(\mathbf{C}-\mathbf{F})$ spleen, $(\mathbf{G})$ peripheral lymph nodes, and $(\mathbf{H})$ peritoneal cavity 18 days after MOG immunization ( $n \geq 4$ mice per group) as determined by immunofluorescence staining with flow cytometry analysis. Within in the histograms, numbers indicate relative percentages of lymphocytes within the indicated gates. Bar graphs indicate (mean \pm SEM) numbers of blood (per $\mathrm{ml}$ ) and tissue $\mathrm{B}$ cells following $\mathrm{mAb}$ treatment. Within the bar graphs, numbers indicate the percentage of $\mathrm{B}$ cells of each phenotype found in CD20 mAb-treated mice (black bars) relative to the numbers of B cells found in control mAb-treated littermates (white bars). Significant differences between CD20 versus control mAb-treated mice are indicated; ${ }^{\star} P<0.05$, ${ }^{\star \star} P<0.01$. Data are representative of at least 2 independent experiments. MZ, marginal zone.

EAE were quantified in vitro using purified mitomycin C-treated antigen-presenting $B$ cells from control $\mathrm{mAb}$-treated mice with EAE. MOG peptide-induced proliferation of $\mathrm{CD} 4^{+} \mathrm{T}$ cells from mice depleted of B cells during EAE development (day 14) was reduced by approximately $60 \%(100 \mu \mathrm{g} / \mathrm{ml} ; P<0.05)$ when compared with $\mathrm{CD} 4^{+} \mathrm{T}$ cells from control $\mathrm{mAb}$-treated littermates
(Figure 6A, right panel). MOG peptide-induced proliferation of $\mathrm{CD}^{+} \mathrm{T}$ cells from mice depleted of $\mathrm{B}$ cells before EAE induction (day -7) was less significantly affected (Figure 6A, left panel). Thus, B cells can present antigens to MOG-specific $\mathrm{T}$ cells, and $B$ cell depletion in vivo significantly reduced antigen-specific $\mathrm{CD} 4^{+} \mathrm{T}$ cell expansion in vitro. 
Table 2

Tissue $B$ cell depletion following EAE induction and CD20 mAb treatment ${ }^{A}$

\begin{tabular}{|c|c|c|c|c|c|}
\hline \multirow[b]{2}{*}{ Tissue } & \multirow[b]{2}{*}{ B cell subsetc } & \multicolumn{2}{|c|}{ Treated day -7 (\% depletion) $)^{B}$} & \multicolumn{2}{|c|}{ Treated day 14 (\% depletion) } \\
\hline & & Control mAb & CD20 mAb & Control mAb & CD20 mAb \\
\hline Bone marrow & $\begin{array}{l}\text { Pro/pre } \\
\text { Immature } \\
\text { Mature }\end{array}$ & $\begin{array}{l}0.10 \pm 0.04 \\
0.16 \pm 0.10 \\
0.48 \pm 0.16\end{array}$ & $\begin{array}{l}0.11 \pm 0.05(0) \\
0.04 \pm 0.02(72) \\
0.01 \pm 0.01\left(99^{D}\right)\end{array}$ & $\begin{array}{l}0.09 \pm 0.03 \\
0.16 \pm 0.04 \\
0.51 \pm 0.14\end{array}$ & $\begin{array}{l}0.09 \pm 0.05(0) \\
0.04 \pm 0.02(72) \\
0.01 \pm 0.01(97 \mathrm{D})\end{array}$ \\
\hline Blood & $\mathrm{B} 220^{+}$ & $3.20 \pm 0.90$ & $0.03 \pm 0.01(99 \mathrm{D})$ & $3.00 \pm 0.70$ & $0.05 \pm 0.02\left(98^{D}\right)$ \\
\hline Spleen & $\begin{array}{c}\text { B220+ }^{+} \\
\text {Mature } \\
\text { T1 } \\
\text { T2 } \\
\text { Marginal zone } \\
\text { CD1d }^{\text {hiCD5 }}{ }^{+}\end{array}$ & $\begin{array}{r}20.00 \pm 6.50 \\
11.40 \pm 4.30 \\
1.50 \pm 0.60 \\
1.20 \pm 0.50 \\
1.90 \pm 0.70 \\
1.10 \pm 0.30\end{array}$ & $\begin{array}{l}0.07 \pm 0.02(99 \mathrm{D}) \\
0.02 \pm 0.02\left(9 \mathrm{~g}^{\mathrm{E}}\right) \\
0.02 \pm 0.02\left(9 \mathrm{~g}^{\mathrm{D}}\right) \\
0.01 \pm 0.01\left(9 \mathrm{~g}^{\mathrm{D}}\right) \\
0.01 \pm 0.02\left(9 \mathrm{gD}^{\mathrm{D}}\right) \\
0.01 \pm 0.01\left(9^{\mathrm{E}}\right)\end{array}$ & $\begin{array}{r}19.60 \pm 1.30 \\
12.60 \pm 1.30 \\
1.40 \pm 0.50 \\
1.30 \pm 0.40 \\
1.90 \pm 0.40 \\
1.20 \pm 0.40\end{array}$ & $\begin{array}{l}1.80 \pm 0.60\left(91^{D}\right) \\
0.68 \pm 0.31\left(95^{D}\right) \\
0.18 \pm 0.07\left(87^{D}\right) \\
0.01 \pm 0.01\left(99^{D}\right) \\
0.01 \pm 0.01\left(99^{D}\right) \\
0.06 \pm 0.02\left(94^{D}\right)\end{array}$ \\
\hline Peripheral LN & $\mathrm{B} 220^{+}$ & $1.20 \pm 0.40$ & $0.05 \pm 0.02\left(95^{\mathrm{D}}\right)$ & $1.20 \pm 0.30$ & $0.43 \pm 0.08\left(65^{\mathrm{D}}\right)$ \\
\hline Peritoneum & $\begin{array}{l}\mathrm{B} 220^{+} \\
\mathrm{B} 1 \mathrm{a} \\
\mathrm{B} 1 \mathrm{~b} \\
\mathrm{~B} 2\end{array}$ & $\begin{array}{l}1.20 \pm 0.20 \\
0.11 \pm 0.03 \\
0.12 \pm 0.04 \\
1.00 \pm 0.40\end{array}$ & $\begin{array}{l}0.01 \pm 0.01\left(99^{\mathrm{E}}\right) \\
0.01 \pm 0.01\left(95^{\mathrm{D}}\right) \\
0.01 \pm 0.01\left(95^{\mathrm{D}}\right) \\
0.01 \pm 0.01\left(99^{\mathrm{D}}\right)\end{array}$ & $\begin{array}{l}1.30 \pm 0.10 \\
0.13 \pm 0.03 \\
0.12 \pm 0.01 \\
1.14 \pm 0.37\end{array}$ & $\begin{array}{l}0.14 \pm 0.08\left(89^{D}\right) \\
0.05 \pm 0.01(62) \\
0.05 \pm 0.02(63) \\
0.13 \pm 0.08\left(90^{D}\right)\end{array}$ \\
\hline
\end{tabular}

AMice were treated with $\mathrm{mAb}(250 \mu \mathrm{g}) 7$ days before or 14 days after MOG immunization. Tissue $B$ cell numbers were determined on day 18 ( $n \geq 4$ mice per value). BValues (mean \pm SEM) indicate cell numbers $\left(\times 10^{-6}\right)$ present in each tissue. ${ }^{\mathrm{C} B}$ cell subsets were as follows: bone marrow, pro/pre $\left(\operatorname{lgM}-\mathrm{B} 220^{\circ}\right)$, immature $\left(\operatorname{lgM}+B 220^{\circ}\right)$, mature (IgM+B220 hi); spleen, mature (CD24+CD21+B220+), T1 (CD24hiCD21-B220+), T2 (CD24hiCD21+B220+), marginal

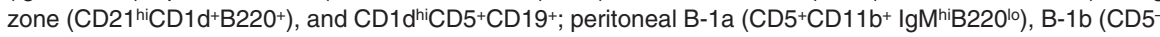

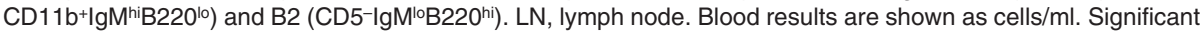
differences between $\mathrm{CD} 20$ versus control mAb-treated mice are indicated; $\mathrm{DP}<0.05, \mathrm{E} P<0.01$.

littermates (Table 3). Thus, $B$ cell depletion did not have global effects on $T$ cell numbers or phenotypes but selectively affected antigen-specific $\mathrm{T}$ cell expansion during the course of disease.

$B 10$ cells regulate EAE. Regulatory IL-10-producing CD $1 d^{\text {hi }} \mathrm{CD}^{+}$B10 cells can inhibit the induction of antigen-specific inflammatory reactions (17). To assess IL-10 production by the spleen CD1d hi ${ }^{-} D 5^{+} B$ cell subset during EAE development, IL-10 transcripts were quantified by real-time PCR analysis. IL-10 transcripts produced by spleen $\mathrm{CD} 1 \mathrm{~d}^{\text {hi }} \mathrm{CD}^{+}$B cells were increased approximately 3-fold during EAE development in comparison with the level of IL-10 transcripts produced by CD $1 \mathrm{~d}^{\text {hi }} \mathrm{CD}^{+} \mathrm{B}$ cells from naive mice (Figure 8A). By contrast, non-CD $1 \mathrm{~d}^{\text {hi }} \mathrm{CD}^{+}$ $B$ cells produced significantly

The effects of B cell depletion on antigen-specific $\mathrm{T}$ cell proliferation in vivo were also assessed by the adoptive transfer of CFSElabeled $\mathrm{CD}^{+} \mathrm{T}$ cells from $\mathrm{TCR}^{\mathrm{MOG}}$ mice (36) on day 17 . Four days after adoptive transfer, CFSE dilution was assessed as a marker for cell divisions by flow cytometry. The numbers of dividing $\mathrm{TCR}^{\mathrm{MOG}} \mathrm{CD}^{+} \mathrm{T}$ cells within the CNS were significantly increased in mice that were depleted of $\mathrm{B}$ cells before EAE induction (132\% increase, $P<0.05$; Figure $6 \mathrm{~B}$ ), while the frequencies and numbers of dividing $\mathrm{TCR}^{\mathrm{MOG}} \mathrm{CD}^{+} \mathrm{T}$ cells within lymph nodes were comparable between mice treated with CD20 or control $\mathrm{mAb}$ before EAE induction (Figure 6C). By contrast, B cell depletion during EAE development (day 14) significantly inhibited the influx of $\mathrm{TCR}^{\mathrm{MOG}} \mathrm{T}$ cells into the CNS ( $82 \%$ decrease, $P<0.05$; Figure $6 \mathrm{~B}$ ) and $\mathrm{TCR}^{\mathrm{MOG}} \mathrm{T}$ cell proliferation within lymph nodes (69\% decrease, $P<0.001$; Figure 6C). Thus, B cell depletion before EAE induction allowed MOG-specific $\mathrm{CD}^{+} \mathrm{T}$ cell expansion within the CNS, whereas $B$ cell depletion during EAE development significantly reduced MOG-specific CD4 ${ }^{+} \mathrm{T}$ cell expansion within the CNS and lymph nodes.

Following B cell depletion on days -7 or 14 , spleen $\mathrm{CD}^{+}$and $\mathrm{CD}^{+} \mathrm{T}$ cell numbers were not changed 18 days after EAE induction (Figure 7A and Table 3). Numbers of spleen naive $\mathrm{CD} 44^{-} \mathrm{CD} 62 \mathrm{~L}^{+}$, activated $\mathrm{CD} 44^{+} \mathrm{CD} 62 \mathrm{~L}^{+}$, memory $\mathrm{CD} 44^{+} \mathrm{CD} 62 \mathrm{~L}^{-}$, and regulatory $\mathrm{CD}_{25}{ }^{+} \mathrm{FoxP}^{+}$(Treg) $\mathrm{CD}^{+}{ }^{+} \mathrm{T}$ cells were not changed following CD20 mAb treatment either before or after EAE induction (Figure 7, A and B, and Table 3). Likewise, CD20 mAb treatment either before EAE induction or during EAE development did not affect lymph node $\mathrm{T}$ cell numbers, subsets, or phenotypes when compared with control mAb-treated
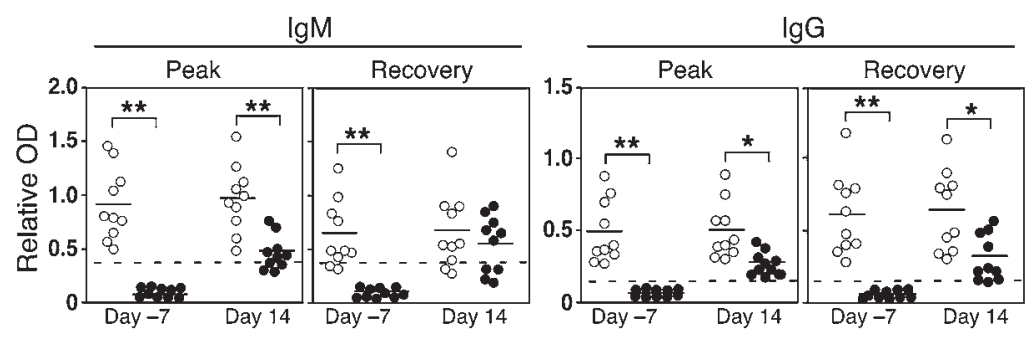

\section{Figure 4}

B cell depletion attenuates MOG-specific antibody production. B6 mice were treated with CD20 (closed circles) or control (open circles) mAb 7 days before or 14 days after MOG immunization. Sera were collected 18 days (peak phase) and 28 days (recovery phase) after MOG immunization, with IgM and IgG MOG-specific antibody levels quantified by ELISA. Horizontal bars indicate mean values. Dashed lines indicate mean MOG-specific antibody values for unimmunized mice $(n=6)$. Significant differences between CD20 and control mAb-treated groups are indicated; ${ }^{*} P<0.01$, ${ }^{* *} P<0.001$. Similar results were obtained in 2 independent experiments. 
A

A Day -7

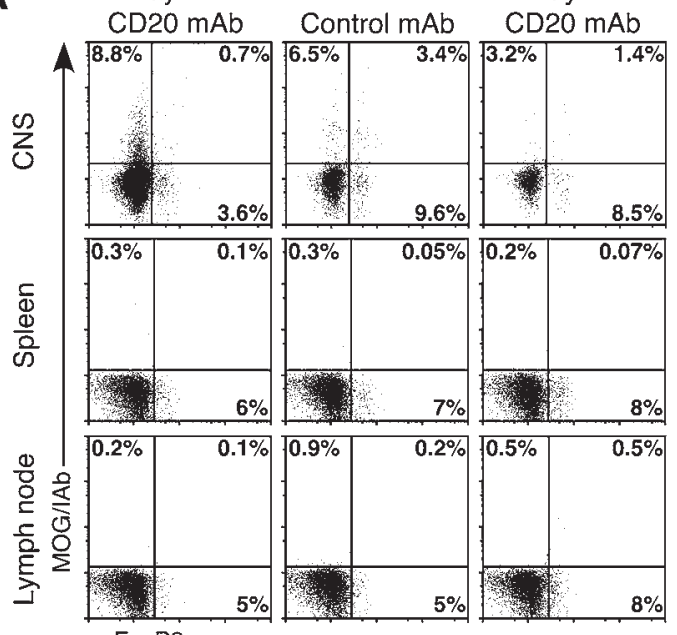

FoxP3
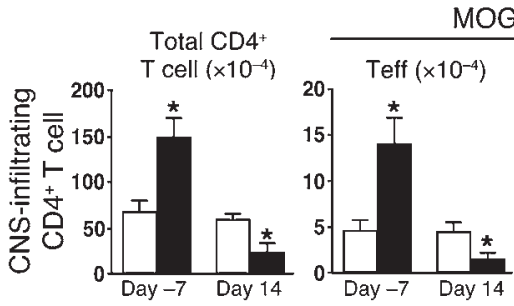

MOG

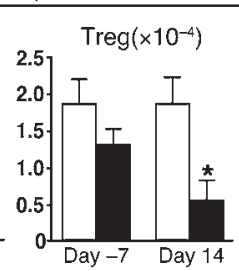

Day 14

B
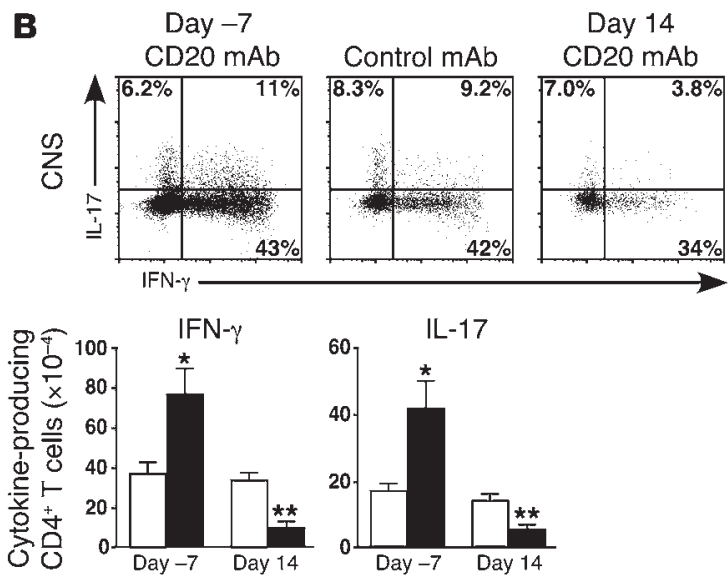

\section{Figure 5}

$B$ cells regulate CNS-infiltrating CD4 ${ }^{+} T$ cell numbers and activation during EAE development. B6 mice were treated with mAb 7 days before or 14 days after MOG immunizations. CNS-infiltrating mononuclear cells were isolated from CNS tissue pooled from more than 3 mice per experiment, while splenocytes and lymph node lymphocytes were isolated from individual mice. (A) Representative histograms showing MOG-specific T cells following CD20 or control mAb treatments as determined by immunofluorescence staining with flow cytometry analysis. CD4+ $\mathrm{T}$ cells were staining with MOG/IAb or control tetramers 18 days after MOG immunizations and assessed by immunofluorescence staining with flow cytometry analysis. Representative MOG-specific Teff (MOG/IAb-tetramer ${ }^{+} \mathrm{CD}^{+}{ }^{+} \mathrm{FoxP}^{-}$) and Treg (MOG/IAbtetramer ${ }^{+} \mathrm{CD}^{+}{ }^{+} \mathrm{FoxP}^{+}$) frequencies are shown within the indicated CD4+ $\mathrm{T}$ cell quadrants. Numbers indicate percentages of $\mathrm{CD}^{+} \mathrm{T}$ cells within each quadrant. Bar graphs indicate numbers (mean \pm SEM, $n \geq 4$ experiments) of CNS-infiltrating $\mathrm{CD}^{+}{ }^{+} \mathrm{T}$ cells and Teff and Tregs, and the ratio of Teff/Tregs following CD20 (black bars) or control mAb (white bars) treatments. (B) IL-17 and IFN- $\gamma$ production by CNS-infiltrating $\mathrm{CD}^{+} \mathrm{T}$ cells 18 days after MOG immunization as determined by intracellular cytokine staining with flow cytometry analysis. Numbers indicate percentages of CD4 ${ }^{+} \mathrm{T}$ cells within the indicated quadrants. Bar graphs indicate numbers (mean \pm SEM, $n \geq 3$ experiments) of CNS-infiltrating $\mathrm{IL}-17^{+}$and IFN- $\gamma^{+} \mathrm{CD} 4^{+}$ $T$ cells following CD20 (black bars) or control mAb (white bars) treatment. ( $\mathbf{A}$ and $\mathbf{B}$ ) Significant differences between sample means are indicated; ${ }^{*} P<0.05,{ }^{\star \star} P<0.01$. Similar results were obtained in at least 2 independent experiments. left panel). By contrast, the adoptive transfer of non-CD1d hi CD5 ${ }^{+}$ $\mathrm{B}$ cells into B cell-depleted mice before EAE induction did not affect EAE severity (Figure 8C, right panel). Furthermore, the adoptive transfer of CD $1 \mathrm{~d}^{\text {hi }} \mathrm{CD}^{+} \mathrm{B}$ cells purified from $\mathrm{Il10} 0^{-/-} \mathrm{Cd} 2 \mathrm{O}^{-/-}$ mice did not affect EAE severity (Figure 8D). Thus, B10 cell IL-10 production negatively regulates EAE initiation.

Whether regulatory B10 cells could attenuate EAE symptoms after disease development was also assessed using $C d 20^{-/-} \mathrm{B}$ cells in adoptive transfer experiments. The adoptive transfer of $\mathrm{CD} 1 \mathrm{~d}^{\text {hi }} \mathrm{CD}^{+}$or non-CD $1 \mathrm{~d}^{\text {hi }} \mathrm{CD}^{+} \mathrm{B}$ cells from $\mathrm{Cd} 2 \mathrm{O}^{-/-}$mice during EAE development (day 14) did not significantly affect the course or severity of disease in B cell-depleted wild-type mice (Figure $8 \mathrm{E})$. Similarly, the adoptive transfer of $\mathrm{CD} 1 \mathrm{~d}^{\text {hi }} \mathrm{CD}^{+} \mathrm{B}$ cells from $\mathrm{Cd} 20^{-/-}$mice into wild-type recipient mice depleted of $\mathrm{B}$ cells on day 14 did not further reduce the severity of EAE beyond the effect of CD20 mAb treatment alone (Figure 8F). These findings suggest that B10 cells are maximally effective early during EAE initiation rather than during disease progression.

\section{Discussion}

These studies show that B cells play critical positive and negative regulatory roles in EAE immunopathogenesis. Consequently, B cell depletion had 2 opposing effects on disease. Early B cell depletion (day -7) in mice with otherwise normal immune systems exacerbated not only the early and peak phase of EAE induction but also the recovery phase of disease (Figure 1). Moreover, the adoptive transfer of IL-10-producing regulatory $\mathrm{CD} 1 \mathrm{~d}^{\text {hi }} \mathrm{CD}^{+} \mathrm{B} 10$ cells, but not other B cells, normalized EAE pathogenesis (Figure 8). Thereby, B cell depletion and removal of the $\mathrm{CD} 1 \mathrm{~d}^{\text {hi }} \mathrm{CD} 5^{+}$regulatory B10 cell subset before EAE induction (day -7; Figure 3) appeared to induce the influx or expansion of encephalitogenic T cells within the CNS (Figure 5 and Figure 6B), which signifi- 
A
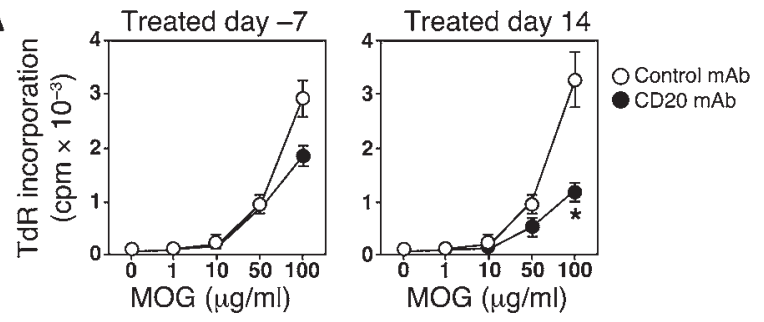

B

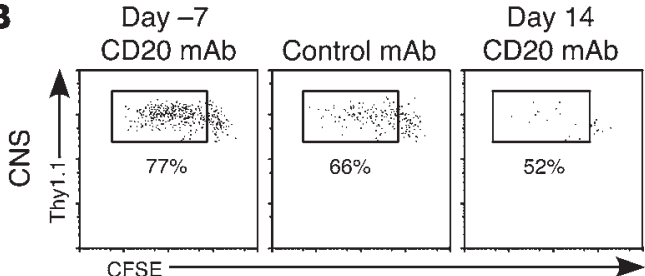

C

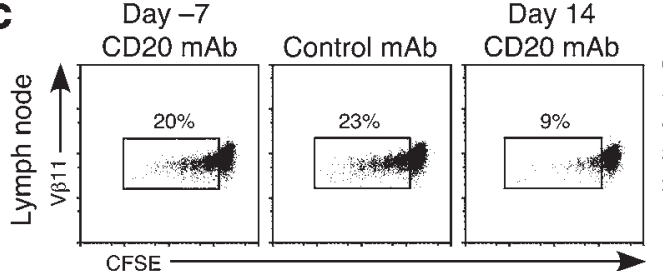

CFSE

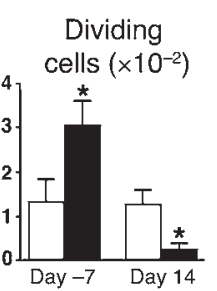

Dividing cells $\left(\times 10^{-4}\right)$

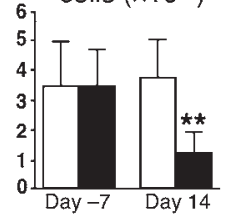

\section{Figure 6}

$\mathrm{B}$ cells regulate MOG-specific CD4+ $\mathrm{T}$ cell expansion. B6 mice were treated with CD20 or control mAb 7 days before or 14 days after MOG immunizations. (A) Eighteen days after MOG immunizations, $C D 4^{+} \mathrm{T}$ cells were purified from superficial lymph nodes and incubated with MOG peptide plus mitomycin C-treated $\mathrm{B}$ cells from control mAb-treated EAE mice ( $n \geq 3$ mice per group). Values indicate (mean \pm SEM) $\left[{ }^{3} \mathrm{H}\right]$-thymidine $(\mathrm{TdR})$ uptake from triplicate cultures. (B) Seventeen days after MOG immunizations, CFSE-labeled TCRMOG CD4+Thy 1.1+ T cells were transferred into Thy 1.2 congenic recipients. Four days later, CNS-infiltrating cells were stained for CD4/Thy1.1 expression and analyzed for CFSE dilution by flow cytometry analysis. Representative frequencies of dividing CFSE-labeled cells are shown (gated on CD4+Thy1.1+ cells). (C) Seventeen days after MOG immunizations, CFSElabeled $\mathrm{TCR}^{\mathrm{MOG}} \mathrm{CD}^{+} \mathrm{T}$ cells were transferred into mice. Four days later, superficial lymph node cells were stained for $\mathrm{V} \beta 11 /$ CD4 expression and analyzed for CFSE dilution by flow cytometry. Representative frequencies of dividing CFSE-labeled cells are shown (gated on $\mathrm{CD}^{+}{ }^{+} \mathrm{V} \beta 11^{+} \mathrm{CFSE}^{+}$cells). (B and $\mathrm{C}$ ) Bar graphs indicate (mean \pm SEM) numbers of dividing TCRMOG T cells following CD20 (black bars) or control mAb (white bars) treatments. Numbers indicate percentages of CFSE-labeled $\mathrm{CD}^{+} \mathrm{T}$ cells. (A-C) Significant differences between CD20 versus control mAb treatment are indicated; ${ }^{*} P<0.05,{ }^{* *} P<0.001$. Similar results were obtained in at least 2 independent experiments. cantly exacerbated disease symptoms (Figures 1 and 2). That B cell depletion enhanced EAE severity in the absence of MOG-specific autoantibodies (Figure 4) also argues that B cells and their antibody products are not required for EAE induction or regulation. Therefore, we propose that increased EAE severity following total $\mathrm{B}$ cell depletion before disease induction results from depletion of the B10 cell subset (Figure 3F).

B cell depletion during the course of EAE development (day 14) dramatically reduced disease symptoms (Figures 1 and 2), impaired MOG-specific T cell expansion (Figure 6, B and C), and significantly inhibited the influx or expansion of encephalitogenic T cells within the CNS and draining lymph nodes (Figures 5 and 6). Thereby, B cells are essential for generating optimal pathogenic $\mathrm{CD}^{+} \mathrm{T}$ cell responses following MOG immunizations, while B10 cells appeared to exert their antiinflammatory effects early, but not late, during the course of EAE (Figure 8). B cells could also serve as antigen-presenting cells to prime MOG-specific T cells (Figure 6A), as shown in previous studies $(13,14)$. However, it is equally possible that $\mathrm{B}$ cells are providing costimulation, an appropriate microenvironment, and/or cytokines that amplify $\mathrm{T}$ cell activation. Thus, the reciprocal positive and negative regulatory roles for B cells are likely to overlap during the course of disease. In support of this, B cell depletion at day 7 before disease symptom onset resulted in a normal course of EAE pathogenesis (Figure 1). Thereby, the balance of at least 2 opposing B cell functions shapes the normal course of EAE immunopathogenesis. This balance is likely to also be reflected in other T cell-mediated autoimmune diseases. However, B cell depletion early, but not late, significantly attenuates the course of collagen-induced arthritis in DBA-1 mice (37), diabetes in NOD mice (38), Sjogren-like disease in Id3-deficient mice (39), and systemic sclerosis-like disease in tight-skin mice (40). These beneficial effects are likely to depend on reduced $\mathrm{CD}^{+} \mathrm{T}$ cell activation, pathogenic $\mathrm{B}$ cell depletion, and reductions in autoantibody production (34). Thereby, B cell contributions during autoimmunity can be divided into distinct pathogenic and regulatory activities.

The current findings resolve previously unexplained contradictions between studies showing the importance of B cells in EAE. As in the current studies, B cell IL-10 production has been previously shown to suppress EAE severity (10). IL-10-produced by $B$ cells can also down-regulate other autoimmune and inflammatory diseases such as collagen-induced arthritis, inflammatory bowel disease, and contact hypersensitivity $(17,41,42)$. By contrast, mice genetically deficient for B cells appear to develop EAE normally but fail to resolve the disease $(7,10)$. However, immune system development and $\mathrm{T}$ cell priming are abnormal in mice lacking B cells since birth (43-45). Thereby, an absence of regulatory B10 cells in combination with abnormal $\mathrm{T}$ cell activation in congenitally B cell-deficient mice may explain normal EAE induction. Regardless, the lack of disease resolution in both models suggests that regulatory B cells may be critical during disease induction and for resolving disease.

EAE pathogenesis is modulated by counter-regulatory B cell subsets and therefore illustrates complexities that must be considered in developing new B cell depletion therapies. However, both pathogenic and regulatory B cell activities may often overlap. For example, B cell depletion 7 days after MOG immunization did not alter the course of EAE (Figure 1). Moreover, the importance of $B$ cells as antigen-presenting or costimulatory cells during disease induction may be negated by EAE induction by use of a potent adjuvant during high-dose MOG immunizations, while B cellmediated $\mathrm{T}$ cell activation may be more important later in the course of disease as antigen concentrations decrease as recently described for other autoantigens and protein antigens (34). Thereby, dendritic cells and other antigen-presenting cells may play a more critical role in antigen presentation or $\mathrm{CD}^{+} \mathrm{T}$ cell activa- 
A
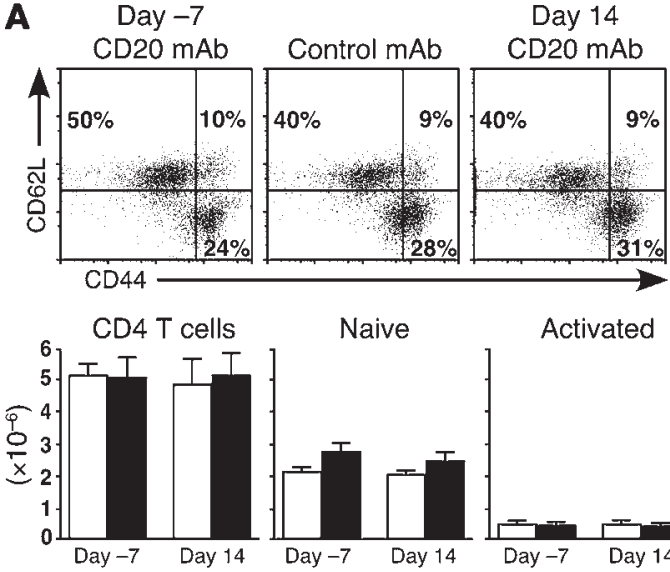

Activated

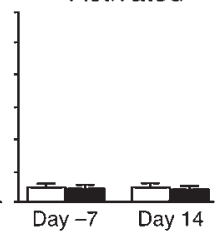

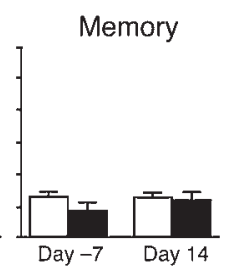

Day 14
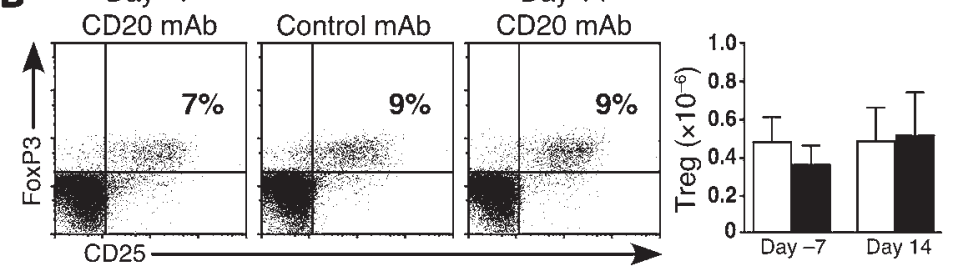

\section{Figure 7}

B cell depletion does not affect splenic CD4+ or Treg numbers during EAE development. Representative flow cytometry analysis of CD4+ $T$ cell subsets 18 days after MOG immunizations ( $n \geq 4$ mice per group): (A) naive, CD4 ${ }^{+} \mathrm{CD} 44-{ }^{-} \mathrm{CD} 62 \mathrm{~L}^{+}$; activated, CD4 ${ }^{+} \mathrm{CD} 44^{+} \mathrm{CD} 62 \mathrm{~L}^{+}$; memory $\mathrm{CD} 4{ }^{+} \mathrm{CD} 444^{+} \mathrm{CD} 62 \mathrm{~L}^{-}$; (B) and Treg, $\mathrm{CD} 4^{+} \mathrm{CD} 25^{+} \mathrm{FoxP}^{+}$. Numbers show relative percentages of lymphocytes within each quadrant. Bar graphs indicate T cell numbers (mean \pm SEM) following CD20 (black bars) or control (white bars) mAb treatments. Similar results were obtained in at least 2 independent experiments. tion during disease initiation, while B cells are maximally important for autoreactive $\mathrm{T}$ cell maintenance during EAE development rather than early EAE initiation. Under these conditions, B cell depletion may only reduce disease during EAE progression, while B10 cell function may be most obvious during disease induction. The current studies also suggest the possibility that the selective depletion of mature B cells while sparing IL-10-producing B10 cells may offer a potent therapeutic approach for treating patients with MS and other autoimmune or inflammatory diseases. However, antigen-specific B10 cells may be required since B10 cells from naive mice were without effect unless they were transferred before MOG immunization (Figure 8, C-F). Our current studies are focused on the identification of pathways that regulate $\mathrm{B} 10$ cell activation, expansion, and function, which will allow this potent $B$ cell subset to be manipulated for therapeutic benefit.

$B$ cell depletion after the onset of EAE symptoms ameliorated disease progression (Figure 1), making this strategy applicable for treating human MS after disease onset. However, adverse disease following B cell depletion before EAE induction in the current study also suggests that B cell depletion may promote the occurrence of MS in some undiagnosed cases. Nonetheless, B cell depletion during EAE development reduced EAE severity both clinically and histologically (Figures 1 and 2) and was accompanied by significantly reduced autoantibody levels (Figure 4). Reduced autoantibody production may be

Table 3 clinically important since plasma exchange can reduce clinical disease activity in a subset of MS patients $(46,47)$. CD20 mAb treatment depletes memory cells in mice but does not deplete long-lived plasma cells (32). Thus, $\mathrm{CD} 20^{+} \mathrm{B}$ cell depletion may be most beneficial when carried out before the long-lived plasma cell pool is established. Similarly, B cell depletion significantly attenuates early foreign- and autoantigen-specific $\mathrm{CD}^{+} \mathrm{T}$ cell proliferation in vivo (34). Also, B cell depletion early in the course of autoimmune mouse models has maximal benefit, as it is often not possible to reverse $\mathrm{T}$ cell expansion or disease progression once inflammatory disease is initiated (37-40). Thereby, B cell depletion shortly after diagnosis of autoimmune disease may offer the most optimal strategy for disease management.

Spleen T cell populations following EAE induction and CD20 mAb treatment ${ }^{A}$

\begin{tabular}{|c|c|c|c|c|c|}
\hline \multirow[b]{2}{*}{ Tissue } & \multirow[b]{2}{*}{ T cell subset } & \multicolumn{2}{|c|}{ Treated day $-7^{B}$} & \multicolumn{2}{|c|}{ Treated day $14^{B}$} \\
\hline & & Control mAb & CD20 mAb & Control mAb & CD20 mAb \\
\hline Spleen & $\begin{array}{c}{\mathrm{CD} 4+C D 3^{+}}^{+} \\
\mathrm{CD} 8+\mathrm{CD} 3^{+} \\
\mathrm{CD} 44^{-} \mathrm{CD} 62 \mathrm{~L}^{+} \mathrm{CD} 4^{+} \\
\mathrm{CD} 44^{+} \mathrm{CD} 62 \mathrm{~L}^{+} \mathrm{CD} 4^{+} \\
\mathrm{CD} 44^{+} \mathrm{CD} 62 \mathrm{~L}^{-} \mathrm{CD} 4^{+} \\
\text {CD25+FoxP3+CD4 }{ }^{+}\end{array}$ & $\begin{array}{l}5.60 \pm 0.30 \\
5.40 \pm 0.30 \\
2.20 \pm 0.10 \\
0.46 \pm 0.07 \\
1.30 \pm 0.20 \\
0.48 \pm 0.12\end{array}$ & $\begin{array}{l}5.30 \pm 0.80 \\
5.90 \pm 0.80 \\
2.90 \pm 0.30 \\
0.39 \pm 0.09 \\
0.90 \pm 0.20 \\
0.33 \pm 0.08\end{array}$ & $\begin{array}{l}5.00 \pm 0.70 \\
5.40 \pm 0.80 \\
2.10 \pm 0.10 \\
0.43 \pm 0.06 \\
1.30 \pm 0.20 \\
0.47 \pm 0.22\end{array}$ & $\begin{array}{l}5.40 \pm 0.80 \\
4.80 \pm 0.60 \\
2.50 \pm 0.30 \\
0.38 \pm 0.05 \\
1.20 \pm 0.20 \\
0.50 \pm 0.24\end{array}$ \\
\hline Peripheral LN & 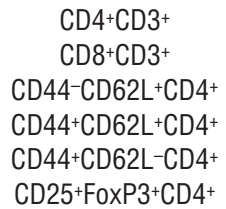 & $\begin{array}{l}1.20 \pm 0.20 \\
1.10 \pm 0.10 \\
1.00 \pm 0.10 \\
0.07 \pm 0.01 \\
0.17 \pm 0.02 \\
0.14 \pm 0.03\end{array}$ & $\begin{array}{l}1.10 \pm 0.20 \\
1.00 \pm 0.30 \\
0.90 \pm 0.30 \\
0.05 \pm 0.02 \\
0.12 \pm 0.04 \\
0.14 \pm 0.02\end{array}$ & $\begin{array}{l}1.10 \pm 0.20 \\
1.00 \pm 0.20 \\
0.90 \pm 0.20 \\
0.06 \pm 0.02 \\
0.17 \pm 0.05 \\
0.14 \pm 0.04\end{array}$ & $\begin{array}{l}1.10 \pm 0.30 \\
1.00 \pm 0.30 \\
0.80 \pm 0.20 \\
0.07 \pm 0.01 \\
0.21 \pm 0.03 \\
0.17 \pm 0.03\end{array}$ \\
\hline
\end{tabular}

${ }^{A}$ Mice were treated with $\mathrm{mAb}(250 \mu \mathrm{g}) 7$ days before or 14 days after MOG immunization, both $\mathrm{T}$ cell numbers determined on day 18 ( $n \geq 4$ mice per value). BValues (mean \pm SEM) indicate cell numbers $\left(\times 10^{-6}\right)$. Lymph node shown as pooled bilateral inguinal and axial lymph nodes. 

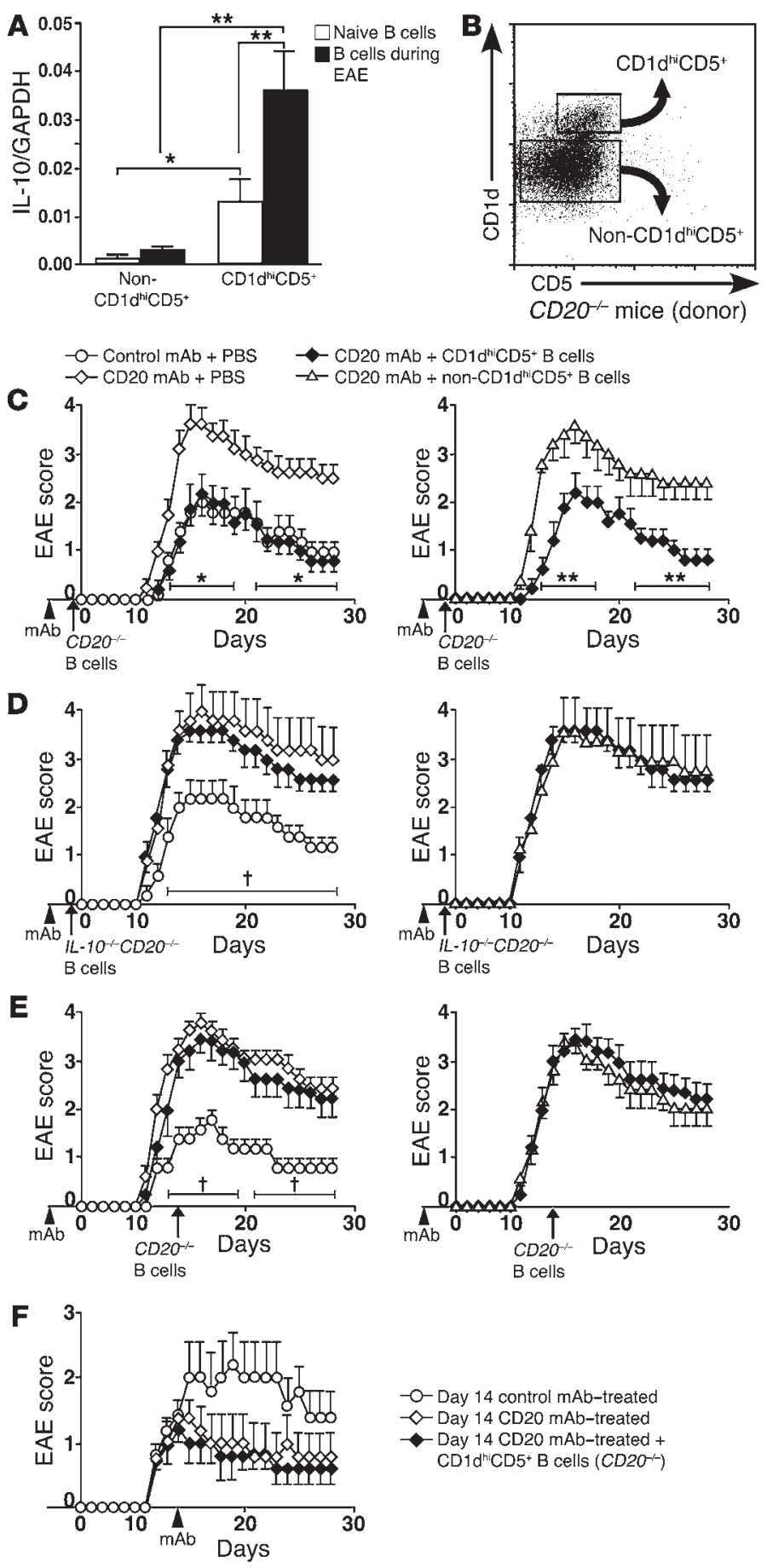

- Day 14 control mAb-treated $\checkmark$ Day 14 CD20 mAb-treated - Day 14 CD20 mAb-treated + CD1d $\mathrm{d}^{\text {riCD5 }}{ }^{+} \mathrm{B}$ cells $\left(\mathrm{CD} 2 \mathrm{O}^{--}\right)$

\section{Methods}

Cell preparation and immunofluorescence analysis. Single-cell leukocyte suspensions from spleens, peripheral lymph nodes (paired axillary and inguinal), and bone marrow (bilateral femurs) were generated by gentle dissection. Mononuclear cells from the CNS were isolated after cardiac perfusion with PBS as described (48). Briefly, CNS tissues were digested with collagenase D $(2.5 \mathrm{mg} / \mathrm{ml}$; Roche Diagnostics) and DNaseI ( $1 \mathrm{mg} / \mathrm{ml}$; Roche Diagnostics) at $37^{\circ} \mathrm{C}$ for $45 \mathrm{~min}$ utes. Mononuclear cells were isolated by passing the tissue through $70-\mu \mathrm{m}$ cell strainers (BD Biosciences), followed by Percoll gradient (70\%/37\%) centrifugation. Lymphocytes were collected from the $37 \% / 70 \%$ interface and washed.

\section{Figure 8}

Regulatory CD1d hi CD5 $+B 10$ cells suppress disease symptoms in EAE. (A) Splenic CD1d hiCD5+ or non-CD1d hiCD5+ B cells were purified from naive mice or mice with EAE (day 10) by cell sorting. RNA was isolated from purified splenic $B$ cells. Values represent relative mean IL-10 transcripts normalized to GAPDH transcript levels (mean \pm SEM, $n \geq 6$ mice per group) as quantified by realtime PCR analysis. Significant differences between sample means are indicated; ${ }^{\star} P<0.05,{ }^{* \star} P<0.01$. Similar results were obtained in at least 2 independent experiments. (B) Representative results showing splenic $\mathrm{CD} 19^{+} \mathrm{B}$ cells from $\mathrm{Cd} 2 \mathrm{O}^{-/-}$mice sorted into regulatory $C D 1 d^{\text {hi }} C D 5^{+}$and nonregulatory $C D 1 d^{\text {hi }} C D 5^{+} B$ cell subsets. (C-E) Wild-type recipient mice that had been treated with CD20 or control mAb 7 days before MOG immunization (arrowheads) were given either purified CD1 $\mathrm{d}^{\text {hi }} \mathrm{CD} 5^{+}$or non-CD1 $\mathrm{d}^{\text {hi }} \mathrm{CD} 5^{+}$ $\mathrm{B}$ cells from (C) naive $\mathrm{Cd} 2 \mathrm{O}^{-/-}$mice 2 days before immunization, (D) naive $1 / 10^{-/-} \mathrm{Cd} 20^{-/-}$mice 2 days before immunization, or (E) naive $\mathrm{Cd} 2 \mathrm{O}^{-/-}$mice 14 days after immunization. (F) Wild-type recipient mice treated with CD20 or control mAb 14 days after MOG immunization (arrowhead) were also given purified CD1 $\mathrm{d}^{\text {hi }} \mathrm{CD}^{+}$ B cells from naive $\mathrm{Cd} 2 \mathrm{O}^{-/-}$mice. Values represent (mean $\pm \mathrm{SEM}$ ) from more than 5 mice in each group, with similar results obtained in 2 independent experiments. Significant differences between the means of EAE clinical scores are indicated: ${ }^{*} P<0.05$ (CD20 $\mathrm{mAb}$ treated plus CD1 $\mathrm{d}^{\text {hi }} \mathrm{CD} 5$ versus mAb treated); ${ }^{*} P<0.05$ (CD20 mAb treated plus CD1 dhiCD5 versus CD20 mAb treated plus non-CD1 dhi $^{\text {h }}$ CD $5^{+}$treated); ${ }^{\dagger} P<0.05$ (CD20 mAb treated plus CD1 $d^{\text {hi }} C D 5$ versus control $m A b$ treated).

Mouse CD20-specific mAb MB20-11 was used as described (31). FITC-, PE- or PE-Cy5-conjugated CD1d (1B1), CD3 (17A2), CD4 (H129.19), CD5 (53-7.3), CD8 (53-6.7), CD19 (1D3), CD25 (PC61), CD44 (IM7), B220 (H1.2F3), Thy1.1 (OX-7), Thy1.2 (53-2.1), and T cell antigen receptor $\mathrm{V} \beta 11$-specific (RR3-15) $\mathrm{mAbs}$ were from $\mathrm{BD}$ Biosciences; anti-IgM mAb (11/41) was from eBioscience. FITC-conjugated $\mathrm{mAb}$ reactive with $\mathrm{L}$-selectin (generated in-house) (CD62L; clone LAM1-116) was as described (49). Intracellular staining used mAbs reactive with IFN- $\gamma$ (XMG1.2), IL-17A (eBio17B7), and FoxP3 (FJK-16s) (all from eBioscience) and the Cytofix/Cytoperm kit (BD Biosciences). For intracellular cytokine staining, lymphocytes were stimulated in vitro with phorbol 12-myristate 13 -acetate $(50 \mathrm{ng} / \mathrm{ml}$; Sigma-Aldrich) and ionomycin ( $1 \mu \mathrm{g} / \mathrm{ml}$; Sigma-Aldrich) in the presence of monensin $\left(1 \mu \mathrm{l} / \mathrm{ml}\right.$; eBioscience) for 4 hours before staining. $\mathrm{MOG}_{38-49} / \mathrm{IAb}$ tetramer and control tetramer (CLIP/IAb) were constructed and supplied by the NIH Tetramer Core Facility. Background staining was assessed using nonreactive, isotype-matched control mAbs (Caltag Laboratories). For 2- or 3-color immunofluorescence analysis, single-cell suspensions $\left(10^{6}\right.$ cells $)$ were stained at $4^{\circ} \mathrm{C}$ using predetermined optimal concentrations of $\mathrm{mAb}$ for 20 minutes as described (50). For tetramer staining, lymphocytes were stained for 3 hours at $37^{\circ} \mathrm{C}$ as described (51). Blood erythrocytes were lysed after staining using FACS Lysing Solution (Becton Dickinson). Cells with the forward and side light scatter properties of lymphocytes were analyzed using a FACScan flow cytometer (Becton Dickinson).

Mice. C57BL/6 (B6) and Il10-/- (B6.129P2-Il10 $\left.{ }^{\mathrm{tm} l \mathrm{Cgn}} / \mathrm{J}\right)$ mice (52) were from The Jackson Laboratory. $C d 20^{-/}$mice were as described (24). $\mathrm{TCR}^{\mathrm{MOG}}$ transgenic mice whose $\mathrm{CD}^{+} \mathrm{T}$ cells respond to $\mathrm{MOG}_{35-55}$ peptide (36) were provided by V.K. Kuchroo (Harvard Medical School, Boston, Massachusetts, USA). TCR ${ }^{\mathrm{MOG}}$ transgenic mice (Thy1.2) were crossed to B6.Thy1.1 mice to generate Thy1.1-expressing T cells for adoptive transfer experiments. $I l 10^{-/-} \mathrm{Cd} 2 \mathrm{O}^{-/-}$mice were generated by interbreeding the $\mathrm{F} 1$ offspring of $\mathrm{Il10^{-/- }}$ and $\mathrm{Cd} 2 \mathrm{O}^{-/-}$mice. Mice were housed in a specific 
pathogen-free barrier facility. The Duke University Animal Care and Use Committee approved all studies.

EAE induction and immunotherapy. Active EAE was induced in 6- to 8-week-old female B6 mice by subcutaneous immunization with $100 \mu \mathrm{g}$ of $M_{35-55}$ peptide (MEVGWYRSPFSRVVHLYRNGK; NeoMPS) emulsified in CFA containing $1 \mathrm{mg} / \mathrm{ml}$ of heat-killed Mycobacterium tuberculosis H37RA (Sigma-Aldrich) on day 0. Additionally, mice received $200 \mathrm{ng}$ of pertussis toxin (List Biological Laboratories) intraperitoneally in $0.5 \mathrm{ml}$ of PBS on days 0 and 2. Clinical signs of EAE were assessed daily with a 0 to 6 point scoring system: 0 , normal; 1 , flaccid tail; 2 , impaired righting reflex and/or gait; 3 , partial hind-limb paralysis; 4 , total hind-limb paralysis; 5 , hind-limb paralysis with partial fore-limb paralysis; 6 , moribund state (10). To deplete $\mathrm{B}$ cells in vivo, sterile CD20 (MB20-11, IgG2c) or isotype-matched control $\mathrm{mAbs}(250 \mu \mathrm{g})$ were injected in $200 \mu \mathrm{l}$ PBS through lateral tail veins (24). Moribund mice were given disease severity scores of 6 and euthanized.

Histology. Following an initial perfusion with PBS, animals were perfused transcardially with $4 \%$ paraformaldehyde and spinal cords were removed. Tissues were processed and blocked in paraffin wax. Transverse sections of the thoracic ( 2 sections) and lumber ( 2 sections) spinal cord were stained with H\&E and Luxol Fast Blue. The number of inflammatory foci that contained at least 20 cells were counted in each H\&E-stained section in a blinded fashion. When foci coalesced, estimates were made of the number of foci $(53,54)$. Areas of demyelination were assessed for Luxol Fast Bluestained sections. ImageJ software (http://rsbweb.nih.gov/ij/) was used to manually trace the total cross-sectional area and the demyelinated area of each section. Total demyelination was expressed as a percentage of the total spinal cord area (55).

Serological evaluation of MOG peptide-specific Ab production. To evaluate MOG peptide-specific Ab production, 96-well microtiter plates (Costar) were coated with $10 \mu \mathrm{g} / \mathrm{ml}$ of MOG peptide. Plates were incubated with serum samples diluted 1:100, with bound antibody detected using alkaline phosphatase-conjugated goat anti-mouse IgG or IgM Abs (Southern Biotechnology Associates Inc.).

Lymphocyte subset isolation. Magnetic cell sorting technology (Miltenyi Biotech) was used to purify lymphocyte populations according to the manufacturer's instructions. CD19 mAb-coated microbeads and CD4 ${ }^{+} \mathrm{T}$ cell isolation kits (Miltenyi Biotech) were used to purify B cells and $\mathrm{CD} 4^{+} \mathrm{T}$ cells, respectively. When necessary, the cells were enriched a second time using a fresh MACS column to obtain more than $95 \% \mathrm{CD} 19^{+}$or $\mathrm{CD} 4^{+}$cell purities, respectively.

In vitro $T$ cell proliferation assays. Eighteen days after MOG immunization, $\mathrm{T}$ cells and $\mathrm{B}$ cells were isolated from lymph nodes and spleen, respectively. Purified T cells $\left(5 \times 10^{5}\right.$ cells $)$ were cultured with mitomycin C-treated (Sigma-Aldrich) B cells $\left(5 \times 10^{5}\right.$ cells) and MOG peptide in 96 -well plates. Proliferation was measured by $\left[{ }^{3} \mathrm{H}\right]$-thymidine incorporation during the final 12 hours of 4-day cultures, followed by scintillation counting.

Cell sorting and adoptive transfer experiments. Donor Thy1.1 CD4 ${ }^{+} \mathrm{T}$ cells were isolated from pooled spleens and lymph nodes of TCR ${ }^{\mathrm{MOG}}$ transgenic mice. $\mathrm{TCR}^{\mathrm{MOG}} \mathrm{CD} 4^{+} \mathrm{T}$ cells were then labeled with CFSE Vybrant CFDA
SE fluorescent dye ( $5 \mu \mathrm{M}$; CFSE; Invitrogen). Labeled TCR ${ }^{\mathrm{MOG}} \mathrm{CD} 4^{+} \mathrm{T}$ cells $\left(5 \times 10^{6}\right.$ cells $)$ were then transferred i.v. into Thy 1.2 congenic recipients. Four days after adoptive transfer, $\mathrm{T}$ cells were assessed by flow cytometry. Splenic B cells were purified from $\mathrm{Cd} 2 \mathrm{O}^{-/-}$mice. In addition, $\mathrm{CD} 1 \mathrm{~d}^{\text {hi }} \mathrm{CD}^{+}$ B cells were isolated using a FACSVantage SE flow cytometer (Becton Dickinson) with purities of $95 \%-98 \%$. After isolation, $2 \times 10^{6} \mathrm{CD} 1 \mathrm{~d}^{\text {hi }} \mathrm{CD}^{+}$ or non-CD $1 \mathrm{~d}^{\text {hi }} \mathrm{CD}^{+} \mathrm{B}$ cells were immediately transferred i.v. into B celldepleted recipient mice.

Real-time RT-PCR. Total RNA was extracted from cell sorter purified B cells using Qiagen RNeasy spin columns (Qiagen). Random Hexamer Primers (Promega) and SuperScript II RNase H Reverse Transcriptase (Invitrogen) were used to generate cDNA. IL-10 transcripts were quantified by real-time PCR analysis using SYBR Green (Bio-Rad) as the detection agent as described. The PCR was performed with the iCycler iQ system (Bio-Rad). All components of the PCR mix were purchased from Bio-Rad and used according to the manufacturer instructions. Cycler conditions were 1 amplification cycle of denaturation at $95^{\circ} \mathrm{C}$ for 3 minutes, followed by 40 cycles of $95^{\circ} \mathrm{C}$ for 10 seconds, $59^{\circ} \mathrm{C}$ for 1 minute, and $95^{\circ} \mathrm{C}$ for 1 minute. Specificity of the RT-PCR was controlled by the generation of melting curves. IL-10 expression threshold values were normalized to GAPDH expression using standard curves generated for each sample by a series of 4 consecutive 10 -fold dilutions of the cDNA template. For all reactions, each condition was performed in triplicate. Data analysis was performed using iCycler (Bio-Rad) analysis software. The sense $I L-10$ primer was $5^{\prime}$-GGTTGCCAAGCCTTATCGGA-3' and the antisense primer was $5^{\prime}$-ACCTGCTCCACTGCCTTGCT-3'. The sense GAPDH primer was $5^{\prime}$-TTCACCACCATGGAGAAGGC- $3^{\prime}$ and the antisense primer was 5'-GGCATGGACTGTGGTCATGA-3'.

Statistics. All data are shown as mean \pm SEM. The significance of differences between sample means was determined using the Student's $t$ test. A $P$ value of less than 0.05 was considered significant.

\section{Acknowledgments}

We thank David Ord, a member of the Tedder laboratory with MS. We thank Caroline Whitacre, NaTosha Gatson, and Vijay Kuchroo for providing mice for these studies. This work was supported by NIH grants (CA105001, CA96547, CA098492, and AI56363). T. Matsushita is supported by a fellowship from Japan Society for the Promotion of Science.

Received for publication April 25, 2008, and accepted in revised form July 23, 2008.

Address correspondence to: Thomas F. Tedder, Box 3010, Department of Immunology, Room 353, Jones Building, Research Drive, Duke University Medical Center, Durham, North Carolina 27710, USA. Phone: (919) 684-3578; Fax: (919) 684-8982; E-mail: thomas.tedder@duke.edu.
1. Williams, K.C., Ulvestad, E., and Hickey, W.F. 1994. Immunology of multiple sclerosis. Clin. Neurosci. 2:229-245.

2. Pettinelli, C.B., and McFarlin, D.E. 1981. Adoptive transfer of experimental allergic encephalomyelitis in SJL/J mice after in vitro activation of lymph node cells by myelin basic protein: requirement for Lyt $1^{+} 2^{-}$ T lymphocytes. J. Immunol. 127:1420-1423.

3. Kuchroo, V.K., et al. 1993. Cytokines and adhesion molecules contribute to the ability of myelin proteolipid protein-specific $\mathrm{T}$ cell clones to mediate experimental allergic encephalomyelitis. J. Immunol. 151:4371-4382.

4. Park, H., et al. 2005. A distinct lineage of CD4
$\mathrm{T}$ cells regulates tissue inflammation by producing interleukin 17. Nat. Immunol. 6:1133-1141.

5. Kennedy, M.K., Torrance, D.S., Picha, K.S., and Mohler, K.M. 1992. Analysis of cytokine mRNA expression in the central nervous system of mice with experimental autoimmune encephalomyelitis reveals that IL-10 mRNA expression correlates with recovery. J. Immunol. 149:2496-2505.

6. Bettelli, E., et al. 1998. IL-10 is critical in the regulation of autoimmune encephalomyelitis as demonstrated by studies of IL-10- and IL-4-deficient and transgenic mice. J. Immunol. 161:3299-3306.

7. Wolf, S.D., Dittel, B.N., Hardardottir, F., and Janeway, C.A., Jr. 1996. Experimental autoimmune encephalomyelitis induction in genetically B celldeficient mice. J. Exp. Med. 184:2271-2278.

8. Cross, A.H., Trotter, J.L., and Lyons, J. 2001. B cells and antibodies in CNS demyelinating disease. J. Neuroimmunol. 112:1-14.

9. Du, C., and Sriram, S. 2002. Increased severity of experimental allergic encephalomyelitis in $\mathrm{lyn}^{-/-}$ mice in the absence of elevated proinflammatory cytokine response in the central nervous system. J. Immunol. 168:3105-3112.

10. Fillatreau, S., Sweenie, C.H., McGeachy, M.J., Gray, D., and Anderton, S.M. 2002. B cells regulate autoimmunity by provision of IL-10. Nat. Immunol. 3:944-950. 
11. Linington, C., Bradl, M., Lassmann, H., Brunner, C., and Vass, K. 1988. Augmentation of demyelination in rat acute allergic encephalomyelitis by circulating mouse monoclonal antibodies directed against a myelin/oligodendrocyte glycoprotein. Am. J. Pathol. 130:443-454.

12. Lyons, J.A., San, M., Happ, M.P., and Cross, A.H. 1999. B cells are critical to induction of experimental allergic encephalomyelitis by protein but not by a short encephalitogenic peptide. Eur. J. Immunol. 29:3432-3439.

13. Bettelli, E., Baeten, D., Jager, A., Sobel, R.A., and Kuchroo, V.K. 2006. Myelin oligodendrocyte glycoproteinspecific T and B cells cooperate to induce a Devic-like disease in mice. J. Clin. Invest. 116:2393-2402.

14. Krishnamoorthy, G., Lassmann, H., Wekerle, H., and Holz, A. 2006. Spontaneous opticospinal encephalomyelitis in a double-transgenic mouse model of autoimmune T cell/B cell cooperation. J. Clin. Invest. 116:2385-2392.

15. Matsushita, T., et al. 2006. Inhibitory role of CD19 in the progression of experimental autoimmune encephalomyelitis by regulating cytokine response. Am. J. Pathol. 168:812-821.

16. Bouaziz, J.-D., Yanaba, K., and Tedder, T.F. 2008 Regulatory B cells as inhibitors of immune responses and inflammation. Immunol. Rev. In press.

17. Yanaba, K., et al. 2008. A regulatory B cell subset with a unique $\mathrm{CD} 1 \mathrm{~d}^{\text {hi }} \mathrm{CD}^{+}$phenotype controls $\mathrm{T}$ cell-dependent inflammatory responses. Immunity. 28:639-650.

18. Edwards, J.C.W., and Cambridge, G. 2001. Sustained improvement in rheumatoid arthritis following a protocol designed to deplete B lymphocytes. Rhenmatology. 40:205-211.

19. Edwards, J.C.W., and Cambridge, G. 2005. Prospects for B-cell-targeted therapy in autoimmune disease. Rheumatology. 44:151-156.

20. El Tal, A.K., Posner, M.R., Spigelman, Z., and Ahmed, A.R. 2006. Rituximab: a monoclonal antibody to CD20 used in the treatment of pemphigus vulgaris. J. Am. Acad. Dermatol. 55:449-459.

21. Anolik, J.H., et al. 2004. Rituximab improves peripheral B cell abnormalities in human systemic lupus erythematosus. Arthritis Rheum. 50:3580-3590.

22. Stasi, R., et al. 2007. Response to B-cell depleting therapy with rituximab reverts the abnormalities of T-cell subsets in patients with idiopathic thrombocytopenic purpura. Blood. 110:2924-2930.

23. Tedder, T.F., and Engel, P. 1994. CD20: a regulator of cell-cycle progression of B lymphocytes. Immunol. Today. 15:450-454.

24. Uchida, J., et al. 2004. Mouse CD20 expression and function. Int. Immunol. 16:119-129.

25. Hauser, S.L., et al. 2008. B-cell depletion with rituximab in relapsing-remitting multiple sclerosis. N. Engl. J. Med. 358:676-688.

26. Goetz, M., Atreya, R., Ghalibafian, M., Galle, P.R., and Neurath, M.F. 2007. Exacerbation of ulcerative colitis after rituximab salvage therapy. Inflamm. Bowel Dis. 13:1365-1368.

27. Dass, S., Vital, E.M., and Emery, P. 2007. Development of psoriasis after B cell depletion with rituximab. Arthritis Rheum. 56:2715-2718.

28. Westermann, J., and Pabst, R. 1991. Lymphocyte subsets in the blood: a diagnostic window on the lymphoid system? Immunol. Today. 11:406-410.

29. Hamaguchi, Y., et al. 2005. The peritoneal cavity provides a protective niche for $\mathrm{B} 1$ and conventional B lymphocytes during anti-CD20 immunotherapy in mice. J. Immunol. 174:4389-4399.

30. Hamaguchi, Y., Xiu, Y., Komura, K., Nimmerjahn, F., and Tedder, T.F. 2006. Antibody isotype-specific engagement of $\mathrm{F}_{\mathrm{C} \gamma}$ receptors regulates $\mathrm{B}$ lymphocyte depletion during CD20 immunotherapy. J. Exp. Med. 203:743-753.

31. Uchida, J., et al. 2004. The innate mononuclear phagocyte network depletes B lymphocytes through $F_{C}$ receptor-dependent mechanisms during antiCD20 antibody immunotherapy. J. Exp. Med. 199:1659-1669.

32. DiLillo, D.J., et al. 2008. Maintenance of longlived plasma cells and serological memory despite mature and memory B cell depletion during CD20 immunotherapy in mice. J. Immunol. 180:361-371.

33. Bettelli, E., et al. 2006. Reciprocal developmental pathways for the generation of pathogenic effector $\mathrm{T}_{\mathrm{H}} 17$ and regulatory $\mathrm{T}$ cells. Nature. 441:235-238.

34. Bouaziz, J.D., et al. 2007. Therapeutic B cell depletion impairs adaptive and autoreactive $\mathrm{CD} 4^{+} \mathrm{T}$ cell activation in mice. Proc. Natl. Acad. Sci. U. S. A. 104:20878-20883.

35. Crawford, A., Macleod, M., Schumacher, T., Corlett, L., and Gray, D. 2006. Primary T cell expansion and differentiation in vivo requires antigen presentation by B cells. J. Immunol. 176:3498-3506.

36. Bettelli, E., et al. 2003. Myelin oligodendrocyte glycoprotein-specific $\mathrm{T}$ cell receptor transgenic mice develop spontaneous autoimmune optic neuritis. J. Exp. Med. 197:1073-1081.

37. Yanaba, K., et al. 2007. B cell depletion delays collagen-induced arthritis in mice: arthritis induction requires synergy between humoral and cell-mediated immunity. J. Immunol. 179:1369-1380.

38. Xiu, Y., et al. 2008. B lymphocytes depletion by CD20 monoclonal antibody prevents diabetes in NOD mice despite isotype-specific differences in $\mathrm{Fc} \gamma \mathrm{R}$ effector functions. J. Immunol. 180:2863-2875.

39. Hayakawa, I., Tedder, T.F., and Zhuang, Y. 2007. B-lymphocyte depletion ameliorates Sjogren's syndrome in Id 3 knockout mice. Immunology. 122:73-79.

40. Hasegawa, M., et al. 2006. B-lymphocyte depletion reduces skin fibrosis and autoimmunity in the tight-skin mouse model for systemic sclerosis. Am. J. Pathol. 169:954-966.

41. Mauri, C., Gray, D., Mushtaq, N., and Londei, M. 2003. Prevention of arthritis by interleukin 10-pro- ducing B cells. J. Exp. Med. 197:489-501.

42. Mizoguchi, A., Mizoguchi, E., Takedatsu, H., Blumberg, R.S., and Bhan, A.K. 2002. Chronic intestinal inflammatory condition generates IL-10-producing regulatory $B$ cell subset characterized by CD1d upregulation. Immunity. 16:219-230.

43. AbuAttieh, M., et al. 2007. Fitness of cell-mediated immunity independent of repertoire diversity. J. Immunol. 178:2950-2960.

44. Chiu, P.P., Serreze, D.V., and Danska, J.S. 2001. Development and function of diabetogenic T-cells in B-cell-deficient nonobese diabetic mice. Diabetes. 50:763-770.

45. Yanaba, K., et al. 2008. B lymphocyte contributions to human autoimmune disease. Immunol. Rev. 223:284-299.

46. Kieseier, B.C., and Hartung, H.P. 2003. Current disease-modifying therapies in multiple sclerosis. Semin. Neurol. 23:133-146.

47. Weinshenker, B.G., et al. 1999. A randomized trial of plasma exchange in acute central nervous system inflammatory demyelinating disease. Ann. Neurol. 46:878-886.

48. Zeine, R., and Owens, T. 1992. Direct demonstration of the infiltration of murine central nervous system by Pgp- $1 / \mathrm{CD} 44^{\text {high }} \mathrm{CD} 45 \mathrm{RB}^{\text {low }} \mathrm{CD} 4^{+} \mathrm{T}$ cells that induce experimental allergic encephalomyelitis. J. Neuroimmunol. 40:57-69.

49. Steeber, D.A., Engel, P., Miller, A.S., Sheetz, M.P., and Tedder, T.F. 1997. Ligation of L-selectin through conserved regions within the lectin domain activates signal transduction pathways and integrin function in human, mouse and rat leukocytes. J. Immunol. 159:952-963.

50. Zhou, L.-J., et al. 1994. Tissue-specific expression of the human CD19 gene in transgenic mice inhibits antigen-independent B lymphocyte development. Mol. Cell. Biol. 14:3884-3894.

51. Falta, M.T., et al. 2005. Class II major histocompatibility complex-peptide tetramer staining in relation to functional avidity and $\mathrm{T}$ cell receptor diversity in the mouse $\mathrm{CD} 4^{+} \mathrm{T}$ cell response to a rheumatoid arthritis-associated antigen. Arthritis Rheum. 52:1885-1896.

52. Kuhn, R., Lohler, J., Rennick, D., Rajewsky, K., and Muller, W. 1993. Interleukin-10-deficient mice develop chronic enterocolitis. Cell. 75:263-274.

53. Sobel, R.A., Tuohy, V.K., Lu, Z.J., Laursen, R.A., and Lees, M.B. 1990. Acute experimental allergic encephalomyelitis in SJL/J mice induced by a synthetic peptide of myelin proteolipid protein. J. Neuropathol. Exp. Neurol. 49:468-479.

54. Marusic, S., et al. 2005. Cytosolic phospholipase $\mathrm{A}_{2} \mathrm{\alpha}$ deficient mice are resistant to experimental autoimmune encephalomyelitis. J. Exp. Med. 202:841-851.

55. Mi, S., et al. 2007. LINGO-1 antagonist promotes spinal cord remyelination and axonal integrity in MOG-induced experimental autoimmune encephalomyelitis. Nat. Med. 13:1228-1233. 